\title{
Novel extracellular RNA biomarkers for early stage hepatocellular cancer
}

\author{
Piyush Gondaliya, Tushar Patel \\ Department of Transplantation, Mayo Clinic, Jacksonville, FL, USA \\ Correspondence to: Dr. Tushar Patel. Department of Transplantation, Mayo Clinic, Jacksonville, FL 32224, USA. Email: patel.tushar@mayo.edu. \\ Comment on: von Felden J, Garcia-Lezana T, Dogra N, et al. Unannotated small RNA clusters associated with circulating extracellular vesicles detect \\ early stage liver cancer. Gut 2021. [Epub ahead of print]. doi: 10.1136/gutjnl-2021-325036.
}

Received: 16 October 2021; Accepted: 08 November 2021; Published: 30 December 2021.

doi: $10.21037 /$ exrna-21-23

View this article at: https://dx.doi.org/10.21037/exrna-21-23

The global burden of hepatocellular carcinoma (HCC) emphasizes the need for surveillance in persons at high risk of cancer such as those with cirrhosis, chronic hepatitis B or other conditions (1). Patients that present with advanced stage cancers have a poor survival. Detection of HCC at early stages can enable the use of curative treatment options and improve long-term survival. The current practice for surveillance for HCC relies on abdominal ultrasound with or without alpha-fetoprotein (AFP) and has limitations. Ultrasound performance can be dependent on patient access, presence of obesity or operator experience. Consequently, the sensitivity of these approaches for the detection of early stage HCC detection is very low (2). While single or individual biomarkers have shown high sensitivity and specificity for HCC, their performance for the detection of early stage disease is unknown. In order to reduce the impact of HCC, there is a need for more effective methods for early detection of HCC (3).

Recent interest has focused on the evaluation of extracellular RNA as potential biomarkers of disease conditions (4). The biological roles of extracellular RNA in HCC are emerging. RNA present within extracellular vesicles (EVs) can contribute towards tumorigenesis, growth and metastases in HCC (5-8). EV can be detected in tissues and body fluids, and thus the detection of $\mathrm{EV}$ RNA appears promising for the detection of diseases associated markers. A variety of different types of RNA may be present within circulating $\mathrm{EV}$, include non-coding RNA, mRNA, and other unannotated RNA species. Regardless of whether or not they subserve a functional biological role, specific RNA that are released by tumors may have potential for use as biomarkers. Given their low abundance, the primary challenge becomes one of adequate detection of differentially expressed extracellular RNA (9). Many detection methods are available for extracellular RNA, but have limited by need for input volume, or rely on targeted discovery. While discovery studies that rely on RNA sequencing may have focused on annotated regions, vast portions of the genome encode for small RNAs that are not annotated.

von Felden et al. (10) report on a novel approach for discovery and use of exRNA for cancer surveillance. They identified a signature comprised of three exRNA small RNA clusters ( $s m R C s$ ) in plasma exRNA as a biomarker that could differentiate patients with early-stage HCC amongst those at higher risk. The authors first used unsupervised small RNA sequencing from serum, urine and tissue samples obtained from 9 patients with prostate cancer to characterize smRC as definable clusters of contiguous genomic regions within unannotated regions. Subsequently, they examined differentially expressed smRCs between 10 patients with HCC, and 5 persons with chronic liver disease and those with non-HCC malignancies. They identified 250 smRCs that were differentially expressed between HCC and controls. A retrospective case-control study was then performed to test the performance of a signature comprised of the three most differentially expressed smRCs for early detection of HCC. The 3-smRC signature had a sensitivity of $86 \%$ and specificity of $91 \%$ for early stage HCC in this study and outperformed the use of ultrasound and serum AFP (Figure 1).

Several questions warrant further assessment. The 


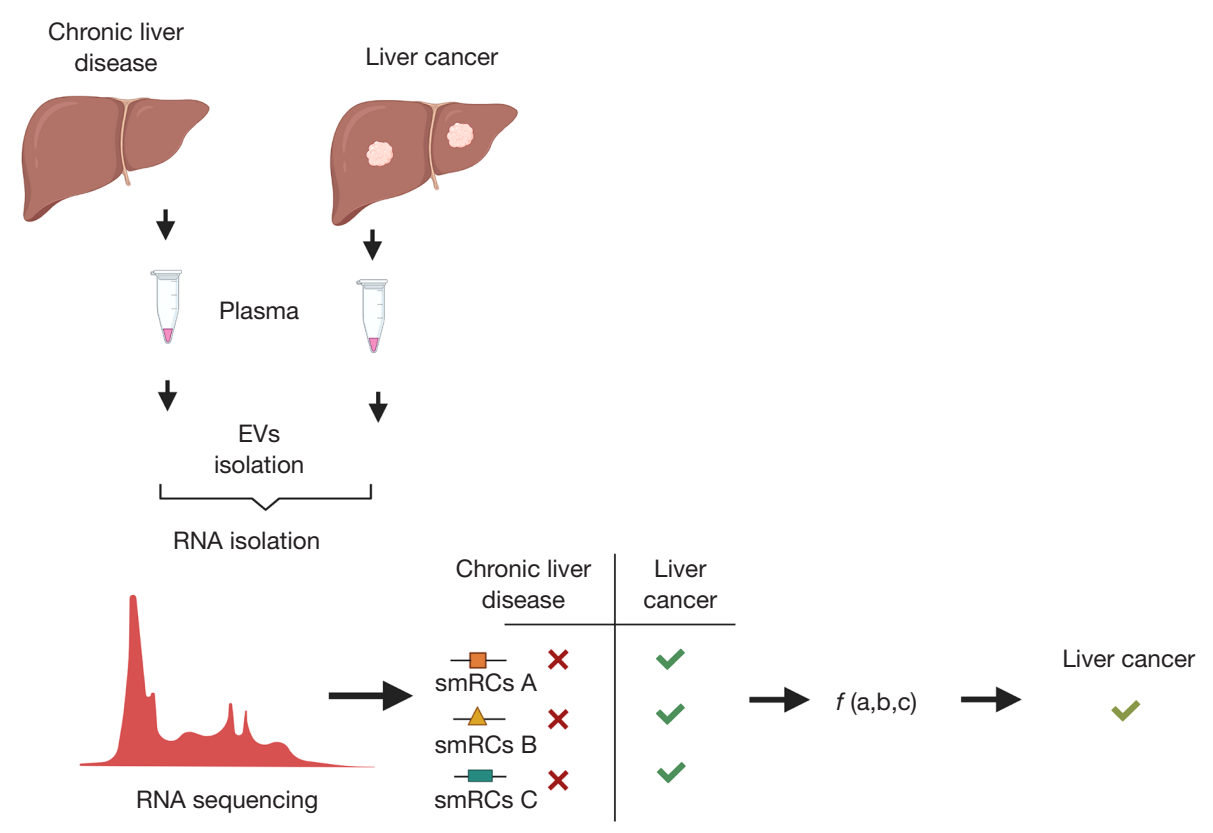

Figure 1 Extracellular RNA biomarkers for liver cancer. EVs, extracellular vesicles; smRCs, small RNA clusters.

approaches used for discovery in the prostate cancer cohort differed from those in HCC cohorts in both the approaches used for separation and well as the biofluids used. Detailed annotation of cellular RNA from liver or HCC cells, and exRNA in plasma samples from HCC would be needed to eliminate the possibility of differences in the types of exRNA isolated using different approaches or from different body fluids. Definition of the extent of overlap between the candidate 3-smRCs and non-human or ribosomal RNA sequences will be helpful. Nevertheless, this report warrants further evaluation of exRNA biomarkers. Blood based biomarkers have advantages over the use of ultrasound and can be more effectively incorporated within clinical practice. Thus, their use may improve surveillance effectiveness of surveillance efforts for detection of early stage HCC. Prior to further use, characterization of the assays used and their performance for broader application has to be defined. Phase III biomarker validation studies in appropriate cohorts of patients with HCC with defined etiologies, gender and other systemic co-morbidities are needed. While their use as biomarkers does not require this, descriptive and mechanistic studies of the role of the candidate smRC and their specificity for HCC will provide biological plausibility. Such studies could further enhance our knowledge of the role of extracellular RNA on oncogenesis.

\section{Acknowledgments}

Funding: The manuscript was supported by National Cancer Institute (CA217833).

\section{Footnote}

Provenance and Peer Review: This article was commissioned by the editorial office, ExRNA. The article has undergone external peer review.

Conflicts of Interest: Both authors have completed the ICMJE uniform disclosure form (available at https://dx.doi. org/10.21037/exrna-21-23). TP reports that financial support for this study was provided by the James C. and Sarah K. Kennedy Deanship, and the Alfred D. and Audrey M. Petersen Professorship. The other author has no conflicts of interest to declare.

Ethical Statement: The authors are accountable for all aspects of the work in ensuring that questions related to the accuracy or integrity of any part of the work are appropriately investigated and resolved.

Open Access Statement: This is an Open Access article distributed in accordance with the Creative Commons 
Attribution-NonCommercial-NoDerivs 4.0 International License (CC BY-NC-ND 4.0), which permits the noncommercial replication and distribution of the article with the strict proviso that no changes or edits are made and the original work is properly cited (including links to both the formal publication through the relevant DOI and the license). See: https://creativecommons.org/licenses/by-nc-nd/4.0/.

\section{References}

1. Yang JD, Hainaut P, Gores GJ, et al. A global view of hepatocellular carcinoma: trends, risk, prevention and management. Nat Rev Gastroenterol Hepatol 2019;16:589-604.

2. Tzartzeva K, Obi J, Rich NE, et al. Surveillance Imaging and Alpha Fetoprotein for Early Detection of Hepatocellular Carcinoma in Patients With Cirrhosis: A Meta-analysis. Gastroenterology 2018;154:1706-18.e1.

3. Yu H, Mei XP, Su PF, et al. A poor prognosis in human hepatocellular carcinoma is associated with low expression of DPP4. Braz J Med Biol Res 2020;53:e9114.

4. Happel C, Ganguly A, Tagle DA. Extracellular RNAs

doi: 10.21037/exrna-21-23

Cite this article as: Gondaliya P, Patel T. Novel extracellular RNA biomarkers for early stage hepatocellular cancer. ExRNA 2021;3:12. as potential biomarkers for cancer. J Cancer Metastasis Treat 2020;6:32.

5. Wang $\mathrm{H}, \mathrm{Lu} Z$, Zhao $\mathrm{X}$. Tumorigenesis, diagnosis, and therapeutic potential of exosomes in liver cancer. J Hematol Oncol 2019;12:133.

6. Thietart S, Rautou PE. Extracellular vesicles as biomarkers in liver diseases: A clinician's point of view. J Hepatol 2020;73:1507-25.

7. Yang N, Li S, Li G, et al. The role of extracellular vesicles in mediating progression, metastasis and potential treatment of hepatocellular carcinoma. Oncotarget 2017;8:3683-95.

8. Xia H, Huang Z, Liu S, et al. Exosomal NonCoding RNAs: Regulatory and Therapeutic Target of Hepatocellular Carcinoma. Front Oncol 2021;11:653846.

9. Sun J, Lu H, Wang X, et al. MicroRNAs in hepatocellular carcinoma: regulation, function, and clinical implications. ScientificWorldJournal 2013;2013:924206.

10. von Felden J, Garcia-Lezana T, Dogra N, et al. Unannotated small RNA clusters associated with circulating extracellular vesicles detect early stage liver cancer. Gut 2021. doi: 10.1136/gutjnl-2021-325036. 